\title{
Walking with the Advanced Reciprocating Gait Orthosis (ARGO) in thoracic paraplegic patients: energy expenditure and cardiorespiratory performance
}

\author{
M Massucci ${ }^{1}$, B Brunetti $^{1}, \mathrm{R}$ Piperno ${ }^{2}, \mathrm{~L} \mathrm{Betti}^{3}$ and M Franceschini ${ }^{1}$ \\ ${ }^{1}$ U.O. di Riabilitazione Intensiva Neuromotoria USL 3, Piazza Garibaldi 5, 06039 Trevi (PG), Italy; ${ }^{2}$ U.O. di \\ Recupero e Rieducazione Funzionale Ospedale Maggiore, USL 108 - Bologna, Italy; ${ }^{3}$ Centro di Riabilitazione 'Luce \\ sul Mare' - Igea Marina (RN), Italy
}

\begin{abstract}
The aim of this study was to quantify the energy cost and the cardiorespiratory response while walking at free speed with an Advanced Reciprocating Gait Orthosis (ARGO). The study was conducted on a group of six male paraplegic patients, age range 16-31 years (median = 22.50), with complete traumatic injuries ranging from $\mathrm{T} 3$ to $\mathrm{T} 12$ and a median time lapse from the trauma of 21 months. The data was recorded 6-8 weeks after the patients were fitted and trained to use the orthosis. Maintaining a standing position produced a significant increase of both the heart rate (HR) and the respiratory rate (RR), whilst the increase of energy consumption was not significant. The data for median speed, energy consumption and energy cost observed during free walking was similar to that of the Reciprocating Gait Orthosis (RGO) in thoracic level paraplegic individuals. This study indicates that in the utilisation of the ARGO the workload is not excessive when it is limited to maintaining a standing position. In contrast, walking results in early anaerobic conditions and unsustainable fatigue after short distances. The great energy cost recorded is considered to be a main reason for the frequent abandonment or the low utilisation of the orthosis at follow-up.
\end{abstract}

Keywords: paraplegic; orthosis; walking; energy cost; energy consumption

\section{Introduction}

There are several problems associated with fitting paraplegic patients with braces and achieving locomotion. Energy demand is a well known crucial aspect of gait performance in paraplegic patients ${ }^{1,2}$ and can enable the clinician to determine the extent to which walking is a practical and suitable strategy of mobility. The most widely used orthoses until the end of the 1970s, namely the knee stabilizing orthosis (KAFO), results in a tiring and poorly cosmetic gait with a swing-through or swing-to pattern. ${ }^{3-5}$ During the last decade great improvements in the field of orthoses have been accomplished through the development of devices enabling the paraplegic individual to ambulate reciprocally. ${ }^{6}$ These devices are more acceptable from an aesthetic point of view, easier to use and allow a more physiological gait pattern. ${ }^{7}$ New efforts have been made to analyse the efficiency of paraplegic reciprocal walking, mainly regarding energy demands. ${ }^{8-11}$

The purpose of this study was to investigate the energy expenditure of gait with a reciprocating orthosis, namely the Advanced Reciprocating Gait

Correspondence: M Massucci, U.O. di Riabilitazione Intensiva Neuromotoria USL 3, Piazza Garibaldi 5, 06039 Trevi (PG), Italy
Orthosis (ARGO), ${ }^{12}$ in a small population of paraplegic subjects with a complete thoracic lesion.

\section{Materials and methods}

Six paraplegic subjects were included in this study and gave their informed consent according to the ethical standards of our institutions. They were fully independent in wheelchair management, driving and transfer. All of them were male, in age ranging from 16-31 years (median 22.50 years), affected by complete paraplegia-grade A according to Frankel ${ }^{13}$ - with lesion levels varying from T3 to T12 (Table 1 shows the details). The duration of the paraplegia varied from 12-51 months (median 21 months). None had any symptoms related to cardiopulmonary function either prior to or at the time of the assessment procedure. Patients with ectopic ossifications, pressure sores and lower limb flexor spasms and/or contractures were also excluded.

\section{Training program}

The ambulation test was performed with the subjects wearing ARGO, custom-made braces which are a 
Table 1 Subjects

\begin{tabular}{|c|c|c|c|c|c|c|}
\hline $\begin{array}{l}\text { Subjects } \\
\text { No. }\end{array}$ & Age (yrs) & $\begin{array}{l}\text { Level of } \\
\text { injury }\end{array}$ & Frankel & $\begin{array}{c}\text { Time since } \\
\text { injury (months) }\end{array}$ & $\begin{array}{c}\text { Weight with } \\
\text { orthosis (kg) }\end{array}$ & $\begin{array}{l}\text { Walking } \\
\text { aids }\end{array}$ \\
\hline 1 & 16 & T3 & A & 12 & 75 & walker \\
\hline 2 & 21 & T5 & A & 19 & 63 & crutches \\
\hline 3 & 22 & T5 & A & 51 & 64 & crutches \\
\hline 4 & 28 & T6 & A & 23 & 77 & walker \\
\hline 5 & 31 & T12 & A & 29 & 73 & crutches \\
\hline 6 & 23 & $\mathrm{~T} 12$ & A & 18 & 98 & crutches \\
\hline
\end{tabular}

development of the Reciprocating Gait Orthosis (RGO). ${ }^{14}$ Each of the patients included had just completed a standard 6-8 week rehabilitation program which included muscle strengthening of the upper body, transferring, putting on and taking off the orthosis, balancing in a standing position, gait training on both regular and irregular surfaces, and stair climbing. After this training program each patient was able to ambulate autonomously with the aid of forearm crutches (subjects 2, 3, 5, 6) or a walker (subjects 1, 4) at a comfortable speed on a regular terrain for at least $30 \mathrm{~m}$.

\section{Ambulation test}

The metabolic parameters of gait were acquired by means of miniature telemetry equipment (Cosmed K2). This device consists of a transmitting unit (weighing about $700 \mathrm{~g}$ ) secured frontally to the chest, a face mask to sample expired gas, a heart rate chest strip, a battery and a fixed receiving unit. A photoelectric turbine flowmeter and a miniaturised polarographic oxygen electrode connected to the face mask, can simultaneously analyze minute ventilation (VE) at body temperature and ambient pressure saturated with water vapour (BTPS) and oxygen concentration in the expired air. The receiver unit is capable of displaying the oxygen uptake $\left(\mathrm{VO}_{2}\right)$ and the main cardiorespiratory parameters. This equipment is easy to use and is quite accurate in comparison with standardised breath to breath systems. ${ }^{15}$ Because Cosmed K2 does not analyze carbon dioxide concentration in the expired gas, it is not able to determine respiratory gas exchange ratio $(\mathrm{R})$. It assumes that $\mathrm{R}$ $=1.00$ for every value of $\mathrm{VO}_{2}$. In practice, change in $\mathrm{R}$ did not have a significant influence on oxygen uptake measurements. This study assessed the physiological parameters of the paraplegic gait in life-like conditions and therefore the equipment which was not cumbersome and was easy to carry was the best suited choice in order to perform long lasting trials in open spaces.

Each trial was performed in the morning, $3 \mathrm{~h}$ after breakfast. The equipment was applied to the subject wearing the orthosis and, given about $60 \mathrm{~min}$ for warming up, the device was then calibrated. The experimental procedure was: $5 \mathrm{~min}$ in the sitting position, $5 \mathrm{~min}$ standing and $5 \mathrm{~min}$ of continuous walk at a comfortable self chosen speed. Data were acquired during the last 2 min of each activity in order to attain a steady state of the performance.

The average speed was calculated dividing the distance covered in the $5 \mathrm{~min}$ of walking. The cardiorespiratory parameters acquired and analyzed in real time were: minute ventilation (VE, BTPS), respiratory rate $(\mathrm{RR})$, tidal volume $(\mathrm{Vt})$, heart rate (HR) and oxygen uptake $\left(\mathrm{VO}_{2}\right)$ at standard temperature and pressure, dry (STPD). We have used the term energy consumption per kilogram mass per minute, to indicate the oxygen uptake divided by the subject's weight. Dividing this figure by the speed gave the energy cost per kilogram per unit of distance covered. The subject's weight was calculated adding the weight of the orthosis to the body weight. The energy cost may also express, in general terms and from a clinical perspective, the mechanical efficiency of gait.

\section{Statistics}

Because of the small sample recruited for the experimental design and the high variability of results, the median instead of the mean value was chosen for descriptive statistics. The comparison between parameters was performed by non parametric statistics (Wilcoxon test) as well as the tests of correlation between variables (Spearman's correlation).

\section{Results}

None of the subjects had cardiovascular abnormalities, while spirometry showed a mild restrictive respiratory deficit (Table 2).

While maintaining an upright standing posture, energy consumption and minute ventilation increased slightly, but the difference with the sitting position values was not statistically significant (Table 3 ). While standing, the two patients with the lowest thoracic lesion level (subject 5 and 6) had slightly lower energy consumption than while sitting $(-11 \%$ and $-12 \%$ respectively). RR and $\mathrm{HR}$ increased reaching a significant level $(P<0.06)$.

Median walking speed was $9.60 \mathrm{~m} / \mathrm{min}$, but it is worth noting that the two subjects using a walker had a lower walking speed than the subjects using forearm 
crutches. During the walking trials all the analyzed parameters clearly showed a significant increase. The heart rate was remarkably higher (median: 156.50 beats/min), revealing in some subjects (cases 3 and 6) a cardiac workload presumably close to the maximal level theoretically possible (with 168 and 171 beats/min respectively). Minute ventilation was further increased $(+195 \%)$ in comparison with the sitting position) as a result of higher respiratory frequency $(+74 \%)$ and tidal volume $(+62 \%)$.

Energy consumption was about three times greater than during sitting rest, with a median value of $13.79 \mathrm{ml} \mathrm{O} 2 / \mathrm{kg} / \mathrm{min}$. Subjects 1 and 3 showed the greatest energy consumption $\left(17.78\right.$ and $16.89 \mathrm{ml} \mathrm{O}_{2} /$ $\mathrm{kg} / \mathrm{min}$ respectively). Energy cost had a median value of $1.28 \mathrm{ml} \mathrm{O} / \mathrm{kg} / \mathrm{m}$ with individual values ranging between 1.05 and $1.97 \mathrm{ml} / \mathrm{kg} / \mathrm{m}$. Such results reveal a very low efficiency of gait in our population of trained patients.

\section{Discussion}

The patients enrolled in this study, on average, had higher cardiorespiratory parameters when standing

Table 2 Pulmonary function. All data expressed as percent predicted values

\begin{tabular}{lccccc}
\hline Subjects & $V C$ & $F V C$ & $F E V_{1}$ & $F E V_{1} / V C$ & $M V V$ \\
\hline 1 & 107 & 107 & 117 & 107 & $/$ \\
2 & 58 & 65 & 64 & 109 & 57 \\
3 & 72 & 75 & 83 & 114 & 54 \\
4 & 87 & 102 & 113 & 128 & 76 \\
5 & 7 & 83 & 84 & 106 & 66 \\
6 & 99 & 104 & 106 & 102 & 118 \\
median & 82.00 & 92.50 & 95.00 & 108.00 & 66.00 \\
\hline
\end{tabular}

Definition of abbreviations: $\mathrm{VC}=$ vital capacity; $\mathrm{FVC}=$ forced vital capacity; $\mathrm{FEV}_{1}=$ forced expiratory volume in one second; $\mathrm{FEV}_{1} / \mathrm{VC}=$ forced expiratory volume in one second/vital capacity ratio; $\mathrm{MVV}=$ maximal voluntary ventilation than when sitting. But only the heart rate (HR) and the respiratory rate $(\mathrm{RR})$ reached significant changes. Increase in $\mathrm{HR}$ can result from the loss of fine sympathetic control below the lesion and impairment of the venous return to the heart. ${ }^{16}$ The increase in $R R$, can be secondary to gravity shifts affecting the length-tension of the diaphragm and also to the loss of synergism of other muscles of the respiratory pump, resulting in shallow breathing. ${ }^{17}$ It is relevant that the increase in the RR and $H R$ in these patients while standing, although statistically significant, never reached exceeding values even for long functional periods of time during day to day activities.

Compared with free walking in normal subjects, the level of energy consumption recorded during ARGO walking is very similar (13.79 vs $13.50 \mathrm{ml} \mathrm{O} 2 / \mathrm{kg} / \mathrm{min})$, while the speed is 10 times lower $(9.60$ vs $89 \mathrm{~m} / \mathrm{min})$ and the energy cost eight times higher (1.28 vs $0.16 \mathrm{mlO}_{2} / \mathrm{kg} / \mathrm{m}$ ). Our subjects exceeded $60 \%$ (subjects 1 and 3 reached $80 \%$ ) of the maximal oxygen uptake for upper limb activity observed in those with thoracic level paraplegia, ${ }^{18}$ while during free walking normal subjects utilise only $35 \%$ of their maximal oxygen uptake. ${ }^{19}$ The anaerobic threshold for upper limb ergometry has been reported to be about $65 \%$ of maximal arm aerobic power. ${ }^{20}$ Hence, the muscular effort during ARGO walking in our study might be compared to a maximal arm ergometry performed in anaerobic conditions. ${ }^{1,21}$ During arm cranking exercise, spinal cord injured patients show a normal ventilatory response. ${ }^{22}$ Our subjects also show a proportional response to work done. During ARGO walking, the minute ventilation doubles compared to resting but, except in subject n.3, remains, on average, $30 \%$ below Maximal Voluntary Ventilation (MVV), leaving most of the functional respiratory reserve still available. Different antropometric characteristics, varying physical fitness of the subjects and age of the lesion may account for high inter-individual variations of minute ventilation $(20.00-51.601 / \mathrm{min})$. Both respiratory rate $(\mathrm{RR})$ and tidal volume $(\mathrm{Vt})$ increased at the same rate as in normal subjects. The increased

Table 3 Energy consumption and cardiorespiratory response in sitting and the standing position, and during walking. In the comparison between parameters, the statistical significance was indicated only for sitting versus standing position (see text for abbreviations)

\begin{tabular}{|c|c|c|c|c|c|c|c|c|c|c|c|c|c|c|}
\hline & & $\begin{array}{c}\mathrm{VO}_{2} \\
\mathrm{ml} / \mathrm{kg} / \mathrm{min}\end{array}$ & & $\begin{array}{c}\mathrm{VO}_{2} \\
\mathrm{ml} / \mathrm{kg} / \mathrm{m}\end{array}$ & & $\begin{array}{c}H R \\
\text { beats/mir }\end{array}$ & & & $\begin{array}{c}V E \\
l / m i n\end{array}$ & & & $\begin{array}{c}R R \\
b r / m i n\end{array}$ & & $\begin{array}{l}\text { Speed } \\
\mathrm{m} / \mathrm{min}\end{array}$ \\
\hline Subjects & $a$ & $b$ & $c$ & $c$ & $a$ & $b$ & $c$ & $a$ & $b$ & $c$ & $a$ & $b$ & $c$ & $c$ \\
\hline 1 & 4.48 & 7.36 & 17.78 & 1.97 & 84 & 84 & 152 & 13.46 & 19.21 & 37.55 & 17.04 & 22.99 & 25.84 & 9 \\
\hline 2 & 5.59 & 8.00 & 12.73 & 1.27 & 99 & 114 & 161 & 12.04 & 12.70 & 31.30 & 23.33 & 23.29 & 27.97 & 10 \\
\hline 3 & 4.99 & 5.61 & 16.89 & 1.05 & 48 & 54 & 168 & 10.15 & 14.94 & 40.53 & 15.87 & 19.22 & 35.58 & 16 \\
\hline 4 & 3.13 & 5.16 & 8.42 & 1.07 & 65 & 78 & 98 & 11.90 & 18.20 & 20.00 & 15.10 & 20.40 & 22.50 & 7.80 \\
\hline 5 & 5.02 & 4.47 & 11.78 & 1.28 & 71 & 88 & 141 & 11.30 & 10.80 & 29.10 & 16.20 & 17.30 & 27.90 & 9.20 \\
\hline 6 & 5.46 & 4.80 & 14.86 & 1.48 & 88 & 89 & 171 & 15.40 & 14.30 & 51.60 & 12.10 & 14.60 & 32.90 & 10 \\
\hline $\begin{array}{l}\text { median } \\
* P<0.06\end{array}$ & 5.00 & 5.39 & 13.79 & 1.28 & 77.50 & $87 *$ & 156.50 & 11.97 & 14.62 & 34.42 & 16.04 & $19.81 *$ & 27.93 & 9.60 \\
\hline
\end{tabular}

$\mathrm{a}$ : sitting position, b: standing position, c: walking 
Table 4 Energy cost and consumption of thoracic paraplegics ambulation in some studies. The speed values and oxygen uptake of the studies are expressed as mean while in this study they are expressed as median

\begin{tabular}{|c|c|c|c|c|c|c|}
\hline Authors & Orthosis & $\begin{array}{c}\text { Number of } \\
\text { subjects }\end{array}$ & $\begin{array}{l}\text { Level of } \\
\text { injury }\end{array}$ & $\begin{array}{l}\text { Speed } \\
m / \text { min }\end{array}$ & $\mathrm{ml} / \mathrm{kg} / \mathrm{min}$ & $\mathrm{ml} / \mathrm{kg} / \mathrm{m}$ \\
\hline Clinkingbeard, 1964 (2) & KAFO & 4 & $\mathrm{~T} 4-\mathrm{T} 12$ & 4.75 & 7.64 & 1.87 \\
\hline Chantrian, 1984 (26) & KAFO & 3 & $\mathrm{~T} 10-\mathrm{T} 11$ & 22.60 & 16.50 & 0.73 \\
\hline Merkel, 1985 (4) & $\begin{array}{c}\text { Scott-Craig } \\
\text { KAFO }\end{array}$ & 6 & $\mathrm{~T} 6-\mathrm{T} 12$ & 10.05 & 12.64 & 1.25 \\
\hline Nene, 1985 (9) & HGO & 10 & $\mathrm{~T} 4-\mathrm{T} 9$ & 12.84 & 9.21 & 0.79 \\
\hline Hirokawa, 1990 (27) & RGO & 6 & $\mathrm{~T} 1-\mathrm{T} 10$ & 12.48 & 13.47 & 1.03 \\
\hline Winchester, 1993 (10) & Isocentric RGO & 4 & $\mathrm{~T} 5-\mathrm{T} 10$ & 13.50 & 13.00 & 1.00 \\
\hline Present study & ARGO & 6 & $\mathrm{~T} 3-\mathrm{T} 12$ & 9.6 & 13.79 & 1.28 \\
\hline
\end{tabular}

activation of the diaphragm and the accessory muscles of the shoulder and neck during this high physical effort, could improve the lack in efficiency of the thoracic pump observed in standing position.

The heart rate also increases proportionally to the work done and reaches very high values (median: 156.50 beats $/ \mathrm{min}$ ). We found a correlation between heart rate and energy consumption. If we exclude the subject with level T3, the correlation is statistically significant $(\mathrm{R}=0.915, P<0.05)$. The excluded subject had a higher energy consumption with a low heart rate, probably due to the damage of the spinal centre of sympathetic regulation of heart, according with the observation of Bar-On and Nene. ${ }^{23}$

The high level of heart rate of subjects walking with ARGO indicates a considerable effort and can be explained considering that normally at a comparable oxygen uptake the heart rate is greater in arm work than in leg work. ${ }^{24}$ Also paraplegics performing a graded arm exercise show an unusually low increase of stroke volume. ${ }^{16}$ This could result from a low venous return to the heart due to a loss of the central sympathetic vasomotor regulation below the injury level. Hence, the cardiovascular overload may be a real limiting factor for walking performance with ARGO in paraplegic individuals.

Comparing our results with previously published studies, one needs to consider that these studies usually present a small number of subjects, a wide range of lesion level and severity of damage, and different assessment protocols (Table 4). Nevertheless, our observations suggest that ARGO can enable patients with a high thoracic lesion to achieve walking with an energy cost similar to that previously demonstrated by subjects with lower level lesion using swing through gait. ${ }^{4}$ This confirms more efficiency in reciprocal walking than in the swing through pattern. ${ }^{11}$ Our data, in accordance with the work of Nene and Patrick ${ }^{9}$ about Hip Guidance Orthosis (HGO), ${ }^{25}$ does not support the close connection of lesion level, energy consumption and walking speed with KAFO suggested by other authors. ${ }^{2,4,26}$ The good stabilization of the upper body supplied by the ARGO, as well as other reciprocating orthoses, may decrease the amount of muscular involvement of both the trunk and the upper limbs and reduce functional differences between patients with different levels of lesion. The energy cost of ARGO walk that we observed is similar to the one reported for the $\mathrm{RGO}^{10,27}$ and higher than the one described for the $\mathrm{HGO}^{9}$ in thoracic paraplegics. Moreover, neither the ARGO nor other modern reciprocating systems can compete with the energy efficiency, speed, precision and ease of use of wheelchair. In fact, from a recent multicentric study in which we participated, ${ }^{28}$ it was learned that $75 \%$ of paraplegic patients 6 months after prescription were already using the $\mathrm{HGO}, \mathrm{RGO}$ and ARGO only for exercise. The ARGO therefore appears more suited for daily therapeutic exercise than for functional walking, taking into account also the different energy cost of the two types of activity.

We conclude that paraplegic ambulation with ARGO, as with the other reciprocating gait orthoses, is not a valid alternative to wheelchair propulsion as far as energy expenditure and energy cost are concerned. Cardiopulmonary load while using ARGO reaches quite an acceptable level during standing. During walking, the workload becomes excessive particularly for the cardiovascular system. Such a workload can only be maintained for a very short time - only a few minutes - and for very short distances. Further studies are needed to evaluate whether better suited training programs including muscle strengthening, endurance exercise and cardiorespiratory fitness, could render using such orthoses less fatiguing, expand their functional usability and reduce the percentage of abandonment during follow up.

\section{Acknowledgements}

We wish to thank the physical therapists who carried out the training of the patients: A Benedetti, N Rosi, C Roldini, R Adriani, A Pergolesi. We also wish to thank Ms Hilary Giles, BA Hans, for the language advice and to RD Ferranti, MD, for his suggestions. This study was supported by 'Regione Umbria ricerca finalizzata' grant. 


\section{References}

1 Gordon EE, Vanderwalde H. Energy requirements in paraplegic ambulation. Arch Phys Med Rehabil 1956; 37: 276-285.

2 Clinkingbeard JR, Gersten JW, Hoehn D. Energy cost of ambulation in traumatic paraplegic. Am J Phys Med 1964; 43: $157-165$.

3 Waters RL, Lunsford BR. Energy cost of paraplegic locomotion. J Bone J Surg (Am) 1985; 67-A: 1245-1250.

4 Merkel KD, Miller NE, Merritt JL. Energy expenditure in patients with low, mid or high thoracic paraplegia using ScottCraig knee-ankle-foot orthoses. Mayo Clin Proc 1985; 60: 165 168.

5 Cerny K, Waters R, Hislop H, Perry J. Walking and wheelchair energetics in persons with paraplegia. Phys Ther 1980; 60: 1133 1139.

6 Nene AV, Hermens HJ, Zilvold G. Paraplegic locomotion: a review. Paraplegia 1996; 34: $507-524$.

7 Stallard J, Major RE, Patrick JH. A review of the fundamental design problems of providing ambulation for paraplegic patients. Paraplegia 1989; 27: $70-75$.

8 Solomonow M et al. The RGO Generation II: muscle stimulation powered orthosis as a practical walking system for thoracic paraplegics. Orthopedics 1989; 12(10): $1309-1315$.

9 Nene AV, Patrick JH. Energy cost of paraplegic locomotion with the ORLAU ParaWalker. Paraplegia 1989; 27: 5-18.

10 Winchester PK et al. A comparison of paraplegic gait performance using two types of reciprocating gait orthoses. Prosthet Orthot Int 1993; 17: $101-106$.

11 Stallard J, Major RE. The influence of orthosis stiffness on paraplegic ambulation and its implications for functional electrical stimulation (FES) walking system. Prosthet Orthot Int 1995; 19: $108-114$

12 Lissene MA, Peeraer L, Goditiabois F, Lysens R. Advanced reciprocating gait orthosis in paraplegic patients. (abstract). In Zupko JK, (ed). Proceedings of the 7th World Congress, International Society for Prosthetics and Orthotics (ISPO), Chicago 1992; p31.

13 Frankel HL et al. The value of postural reeducation in the management of the closed injuries to the spine with paraplegia and tetraplegia. Paraplegia 1969; 7: 179-192.
14 Beckham J. The Lousiana State University Reciprocating Gait Orthosis. Physiotherapy 1987; 8: 24-30.

15 Crandall CG, Taylor SL, Raven PB. Evaluation of the Cosmed K2 portable telemetric oxygen uptake analyzer. Med Sci Sports Exerc 1994; 26: $108-111$.

16 Hjeltnes N. Oxygen uptake and cardiac output in graded arm exercise in paraplegics with low level spinal lesions. Scand $J$ Rehabil Med 1977; 9: $107-113$.

17 Chen CF, Lien IN, Wu MC. Respiratory function in patients with spinal cord injuries: effects of posture. Paraplegia 1990; 28: $81-86$.

18 Coutts KD, Rhodes EC, McKenzie DC Maximal exercise responses of tetraplegics and paraplegics. $J$ Appl Physiol: Respirat Environ Exercise Physiol 1983; 55(2): 479-482.

19 Blessey RL, Hislop HJ, Waters RL, Antonelli D. Metabolic energy cost of unrestrained walking. Phys Ther 1976; 56: 10191024.

20 Reybrouck T, Heigenhauser GF, Faulkner JA. Limitation to maximal oxygen uptake in arm, leg and combined arm-leg ergometry. J Appl Physiol 1975; 38: 774-779.

21 Huang CT, Kuhlemeier KV, Moore NB, Fine PR. Energy cost of ambulation in paraplegic patients using Craig-Scott braces. Arch Phys Med Rehabil 1979; 60: 595-600.

22 Coutts KD, Rhodes EC, McKenzie DC. Submaximal exercise responses of tetraplegics and paraplegics. J Appl Pysiol 1985; 59(1): $237-241$.

23 Bar-On ZH, Nene AV. Relationship between heart rate and oxygen uptake in thoracic level paraplegics. Paraplegia 1990; 28: $87-95$.

24 Astrand PO, Rodahl. 2nd ed. McGraw-Hill, New York. Textbook of Work Physiology 1977.

25 Moore F. The parawalker: walking for thoracic paraplegics. Physiother Pract 1989; 4: 18-22.

26 Chaintraine A, Crielaard JM, Onkelinx A, Pirnay F. Energy expenditure of ambulation in paraplegics: effects of long term use of bracing. Paraplegia 1984; 22: 173-181.

27 Hirokawa $\mathrm{S}$ et al. Energy consumption in paraplegic ambulation using the reciprocating gait orthosis and electric stimulation of the thigh muscles. Arch Phys Med. Rehabil 1990; 71: 687-694.

28 Lotta S et al. Restoration of gait with orthoses in thoracic paraplegia: a multicentric investigation. Paraplegia 1994; 32: $608-615$. 